\title{
Fabrication of 3D Amino-Functionalized Metal-Organic Framework on Porous \\ Nickel Foam Skeleton to Combinate Follicle Stimulating Hormone Antibody \\ for Specific Recognition of Follicle-Stimulating Hormone
}

Sathyadevi Palanisamy ${ }^{\mathrm{a}, \dagger}$, Hsu-Min $\mathrm{Wu}^{\mathrm{a}, \dagger}$, Li-Yun Lee $^{\mathrm{a}}$, Shyng-Shiou F. Yuan ${ }^{\mathrm{b}, \mathrm{c}, \mathrm{d}}$, and Yun-Ming Wang ${ }^{\mathrm{a}, \mathrm{e}, ~ *}$

a Department of Biological Science and Technology, Institute of Molecular Medicine and Bioengineering, Center for Intelligent Drug Systems and Smart Bio-devices (IDS ${ }^{2}$ B), National Yang Ming Chiao Tung University, 75 Bo-Ai Street, Hsinchu 300, Taiwan.

${ }^{\mathrm{b}}$ Translational Research Center, Kaohsiung Medical University Hospital, Kaohsiung Medical University, Kaohsiung 807, Taiwan.

${ }^{\mathrm{c}}$ Department of Obstetrics and Gynecology, Kaohsiung Medical University Hospital, Kaohsiung Medical University, Kaohsiung 807, Taiwan.

${ }^{\mathrm{d}}$ Faculty and College of Medicine, Kaohsiung Medical University, Kaohsiung 807, Taiwan.

e Department of Biomedical Science and Environmental Biology, Department of Dentistry, Center for Cancer Research, Kaohsiung Medical University, Kaohsiung 807, Taiwan.

$\dagger$ These two authors contributed equally

* Corresponding author:

Prof. Yun-Ming Wang

Department of Biological Science and Technology

Institute of Molecular Medicine and Bioengineering

Center for Intelligent Drug Systems and Smart Bio-devices (IDS ${ }^{2}$ B)

National Yang Ming Chiao Tung University

75 Bo-Ai Street, Hsinchu 300, Taiwan.

Tel: 886-3-5712121 ext. 56972; Fax, 886-3-5729288

E-mail address: ymwang@mail.nctu.edu.tw 


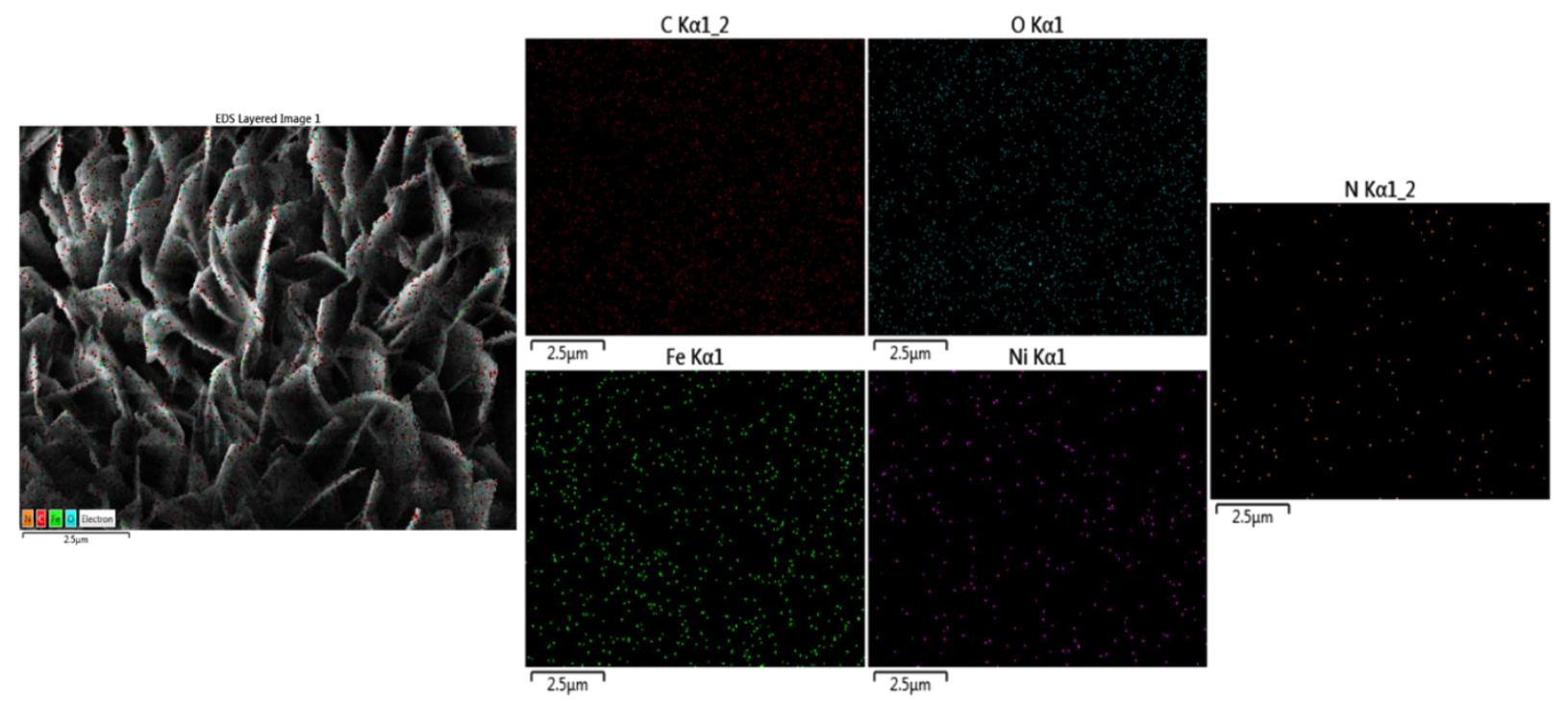

Figure S1. SEM-EDX area elemental mapping images $\mathrm{H}_{2} \mathrm{~N}-\mathrm{Fe}-\mathrm{MIL}-101$ showing the distributions of $\mathrm{C}, \mathrm{O}, \mathrm{Fe}$, and $\mathrm{Ni}$ grown on $\mathrm{NicF}$.
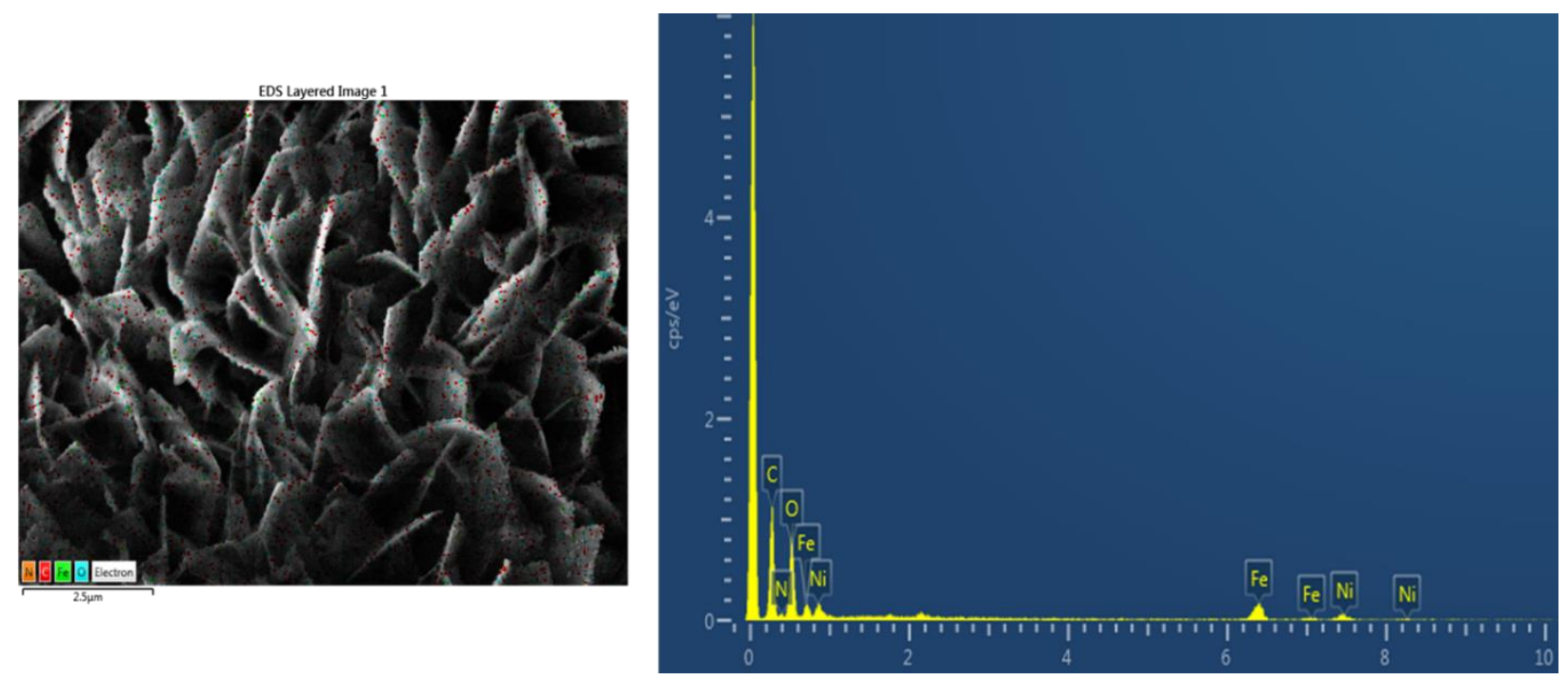

Figure S2. SEM-EDX area elemental mapping images of $\mathrm{H}_{2} \mathrm{~N}-\mathrm{Fe}-\mathrm{MIL}-101$ grown on NicF. 

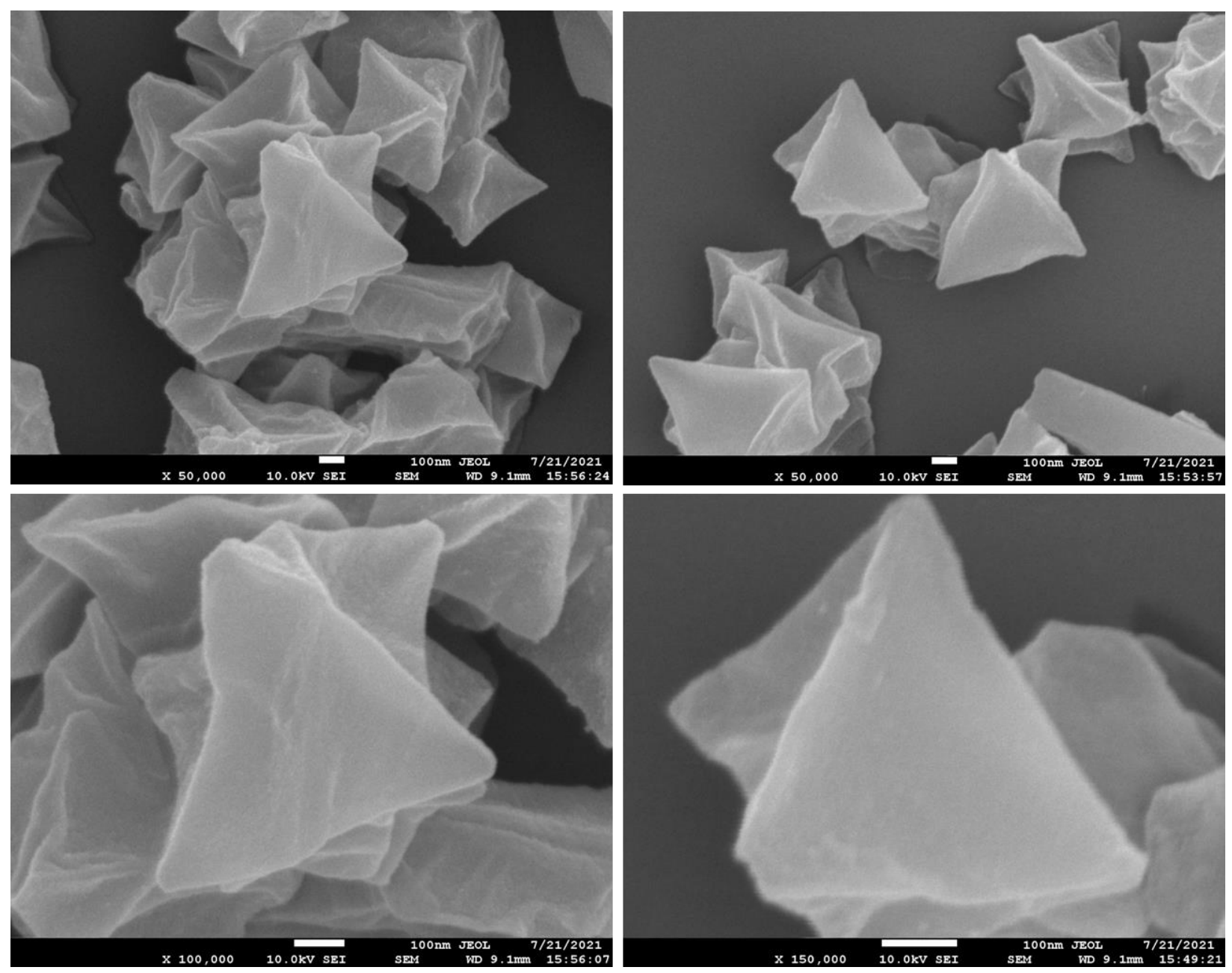

Figure S3. SEM images of the sonicated $\mathrm{H}_{2} \mathrm{~N}-\mathrm{Fe}-\mathrm{MIL}-101$ particle 

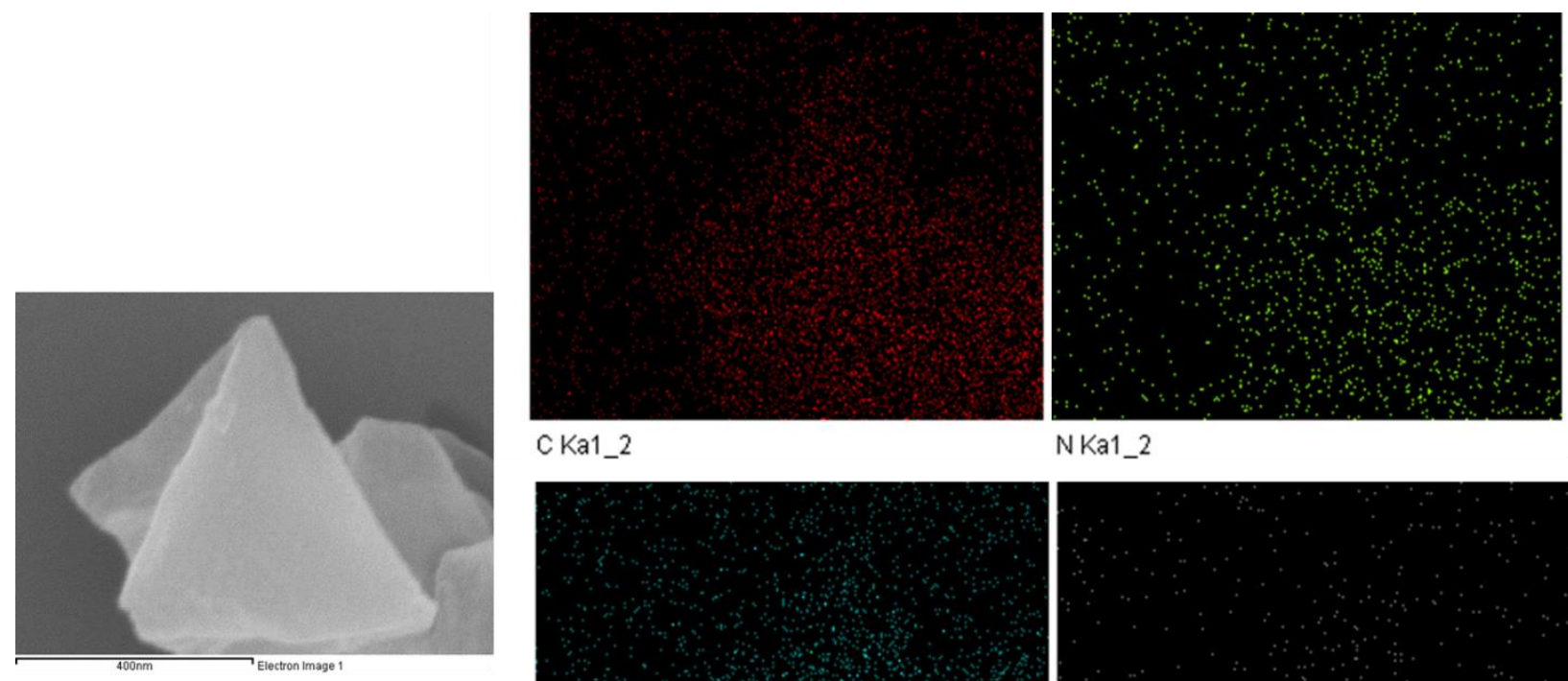

CKa1_2

NKa1_2
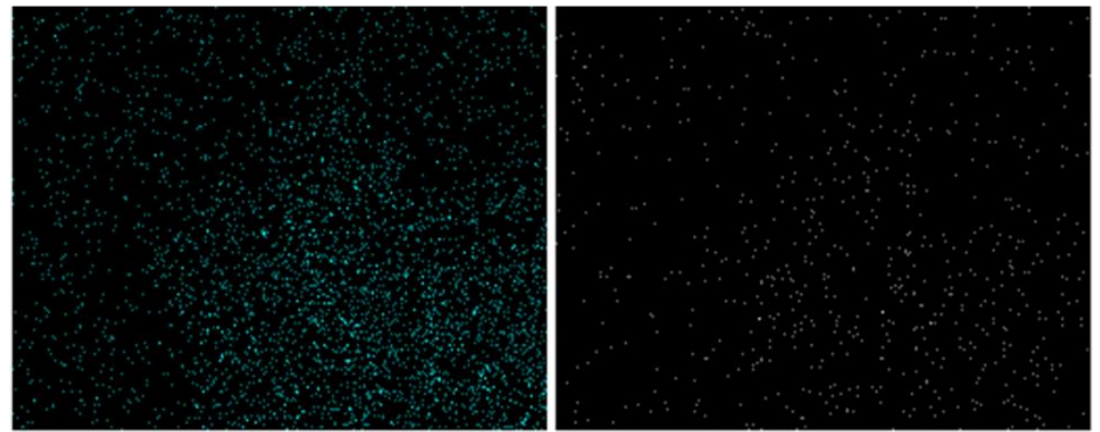

O Ka1

Fe Ka1

Figure S4. SEM-EDX area elemental mapping images of the sonicated $\mathrm{H}_{2} \mathrm{~N}-\mathrm{Fe}-\mathrm{MIL}-101$ particle.

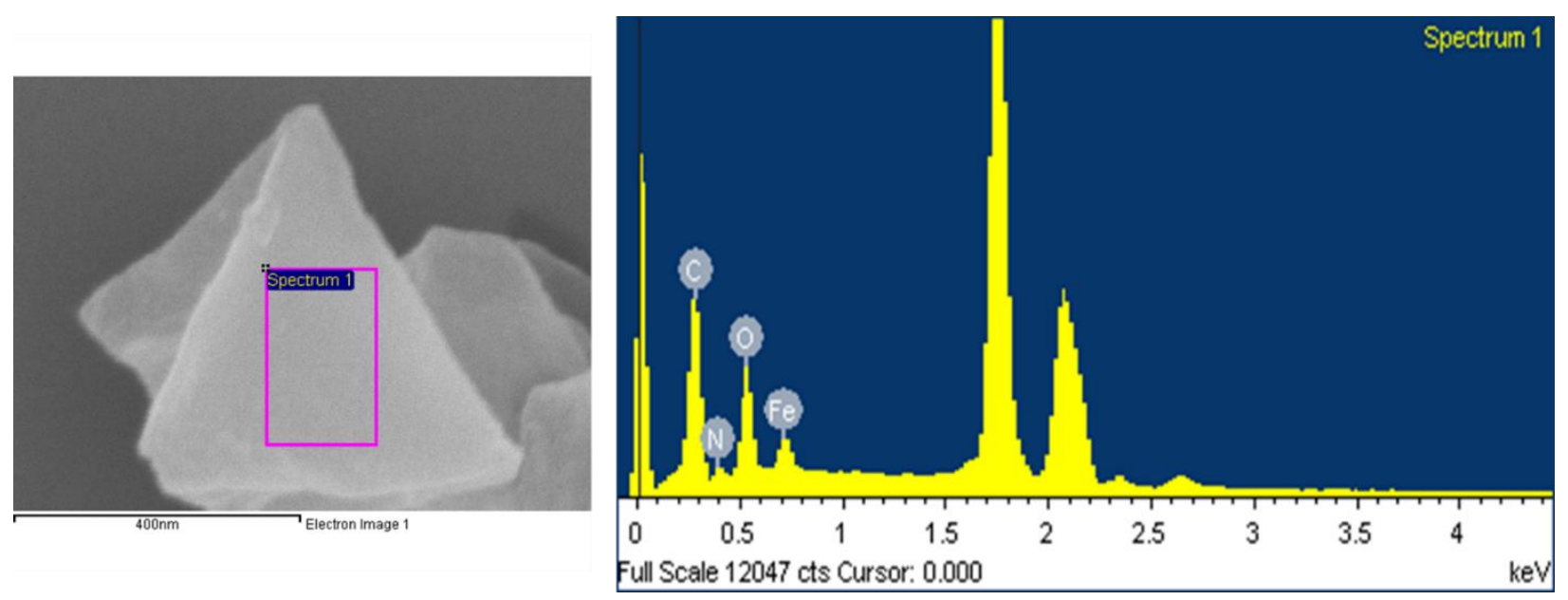

Figure S5. SEM-EDX area elemental mapping images of the sonicated $\mathrm{H}_{2} \mathrm{~N}-\mathrm{Fe}-\mathrm{MIL}-101$ particle. 


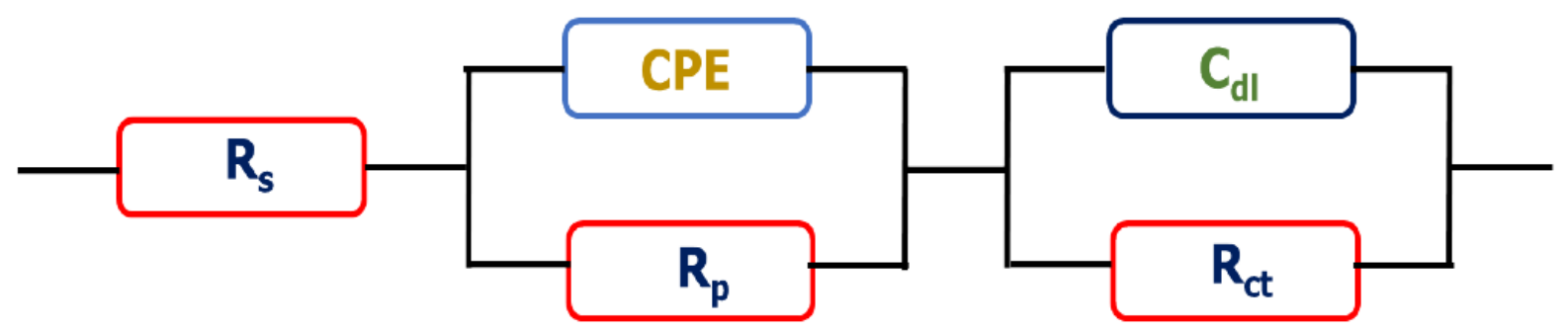

Figure S6. Equivalent circuit model for the electrochemical impedance FSH detection. $\mathrm{R}_{\mathrm{s}}, \mathrm{R}_{\mathrm{p}}$, and $\mathrm{R}_{\mathrm{ct}}$, represent the electrolyte, electrode porosity, and charge transfer resistance, respectively, whereas the $\mathrm{CPE}$ and $\mathrm{C}_{\mathrm{dl}}$ represent the constant phase element and double layer capacitance respectively.

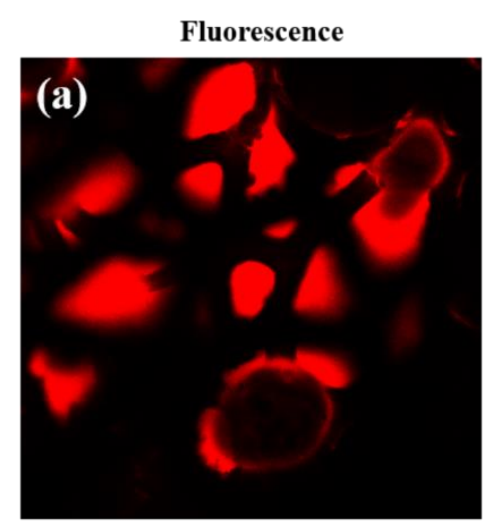

Rhod B dye

treated

$\mathrm{H}_{2}$ N-Fe-MIL-101/NicF

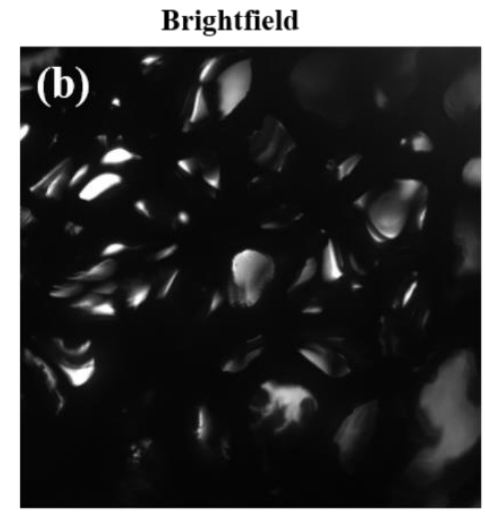

Ab-FSH

treated

$\mathrm{H}_{2} \mathrm{~N}-\mathrm{Fe}-\mathrm{MIL}-101 / \mathrm{NicF}$

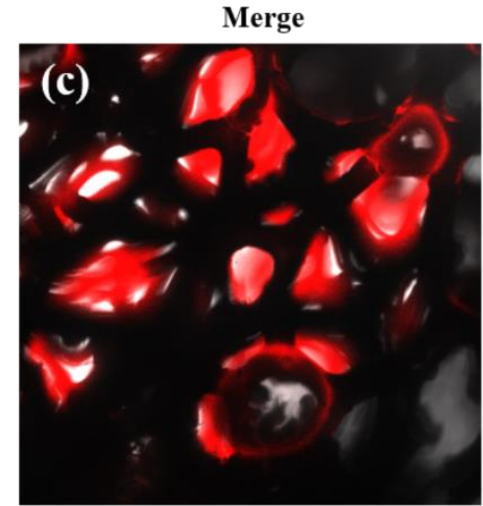

Rhod B dye/Ab-FSH treated $\mathrm{H}_{2} \mathrm{~N}-\mathrm{Fe}-\mathrm{MIL}-101 / \mathrm{NicF}$

Figure S7. Confocal laser screening microscopy of $\mathrm{H}_{2} \mathrm{~N}-\mathrm{Fe}-\mathrm{MIL}-101 / \mathrm{NicF}$ electrodes after incubation with Rhod B dye and Ab-FSH. (a). Rhod B dye treated $\mathrm{H}_{2} \mathrm{~N}-\mathrm{Fe}-\mathrm{MIL}-101 / \mathrm{NicF}$. (b) Ab-FSH treated $\mathrm{H}_{2} \mathrm{~N}-\mathrm{Fe}-\mathrm{MIL}-101 / \mathrm{NicF}$. (c) Rhod B dye/Ab-FSH treated $\mathrm{H}_{2} \mathrm{~N}-\mathrm{Fe}-\mathrm{MIL}-$ 101/NicF. 


\section{Stability of $\mathrm{H}_{2} \mathrm{~N}-\mathrm{Fe}-\mathrm{MIL}-101 / \mathrm{NicF}$ electrodes and Ab-FSH/H $2 \mathrm{~N}-\mathrm{Fe}-\mathrm{MIL}-101 / \mathrm{NicF}$ electrodes}

The acidic and basic stability of $\mathrm{H}_{2} \mathrm{~N}-\mathrm{Fe}-\mathrm{MIL}-101 / \mathrm{NicF}$ is given in Figure S8. To check the chemical stability, the SEM images of $\mathrm{H}_{2} \mathrm{~N}-\mathrm{Fe}-\mathrm{MIL}-101 / \mathrm{NicF}$ electrodes and Ab-FSH combined $\mathrm{H}_{2} \mathrm{~N}-\mathrm{Fe}-\mathrm{MIL}-101 / \mathrm{NicF}$ electrodes were recorded after $24 \mathrm{~h}$ at different $\mathrm{pH}(\mathrm{pH}=4$ and $\mathrm{pH}=10)$. No significant changes in the morphologies were noticed. These results revealed that $\mathrm{H}_{2} \mathrm{~N}-\mathrm{Fe}-$ MIL-101/NicF and Ab-FSH/ $\mathrm{H}_{2}$ N-Fe-MIL-101/NicF are stable under acidic and basic conditions. To check the mechanical stability, the electrodes were kept in a mechanical shaker in PBS buffer for $24 \mathrm{~h}$ and then recorded their SEM images (Figure S9). No significant changes in their morphologies supporting the mechanical stability of $\mathrm{H}_{2} \mathrm{~N}-\mathrm{Fe}-\mathrm{MIL}-101 / \mathrm{NicF}$ and $\mathrm{Ab}-\mathrm{FSH} / \mathrm{H}_{2} \mathrm{~N}$ Fe-MIL-101/NicF electrodes. 


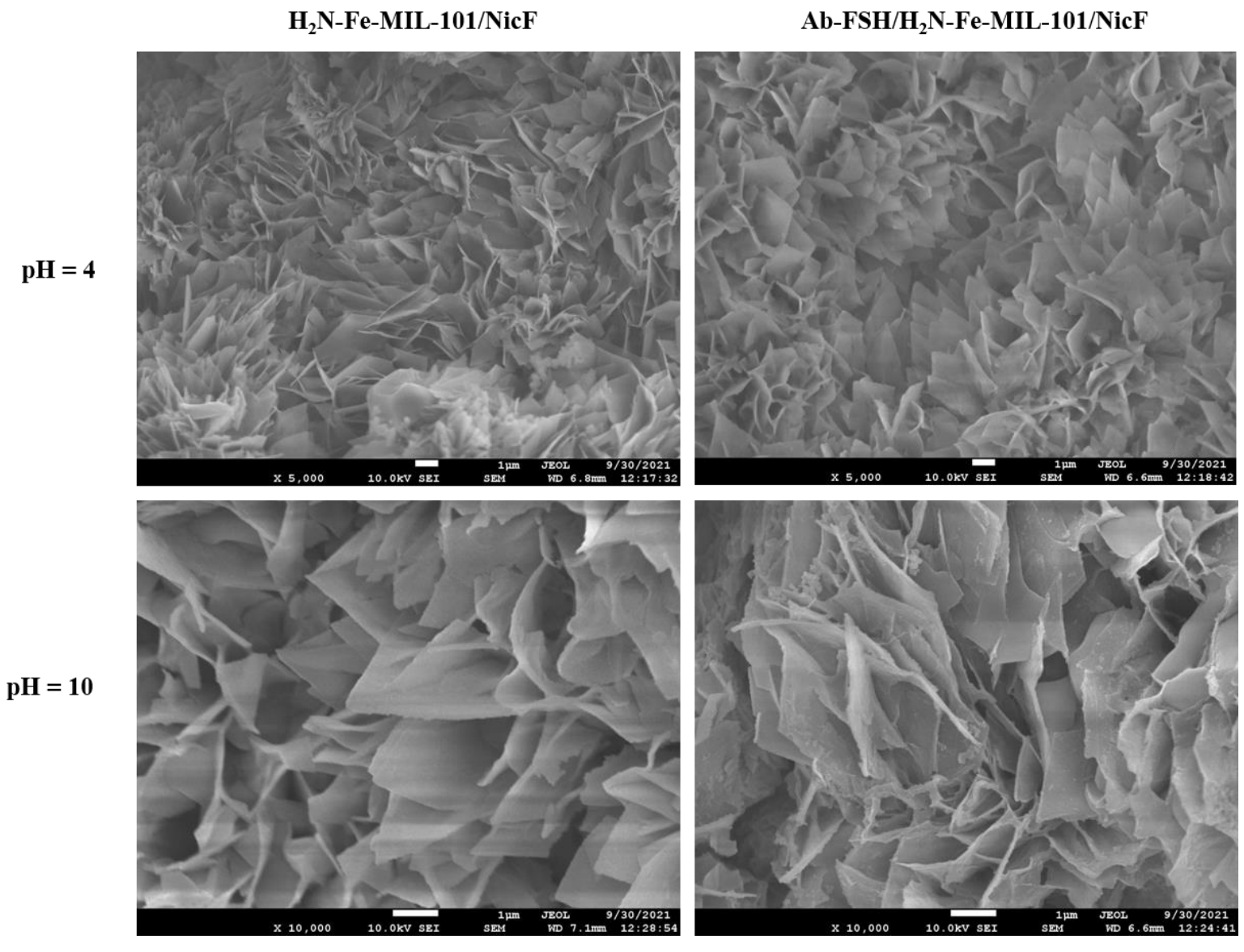

Figure S8. Stability analysis of $\mathrm{H}_{2} \mathrm{~N}-\mathrm{Fe}-\mathrm{MIL}-101 / \mathrm{NicF}$ electrodes and Ab-FSH/H $2 \mathrm{~N}-\mathrm{Fe}-\mathrm{MIL}-$ 101/NicF electrodes under acidic and basic conditions.
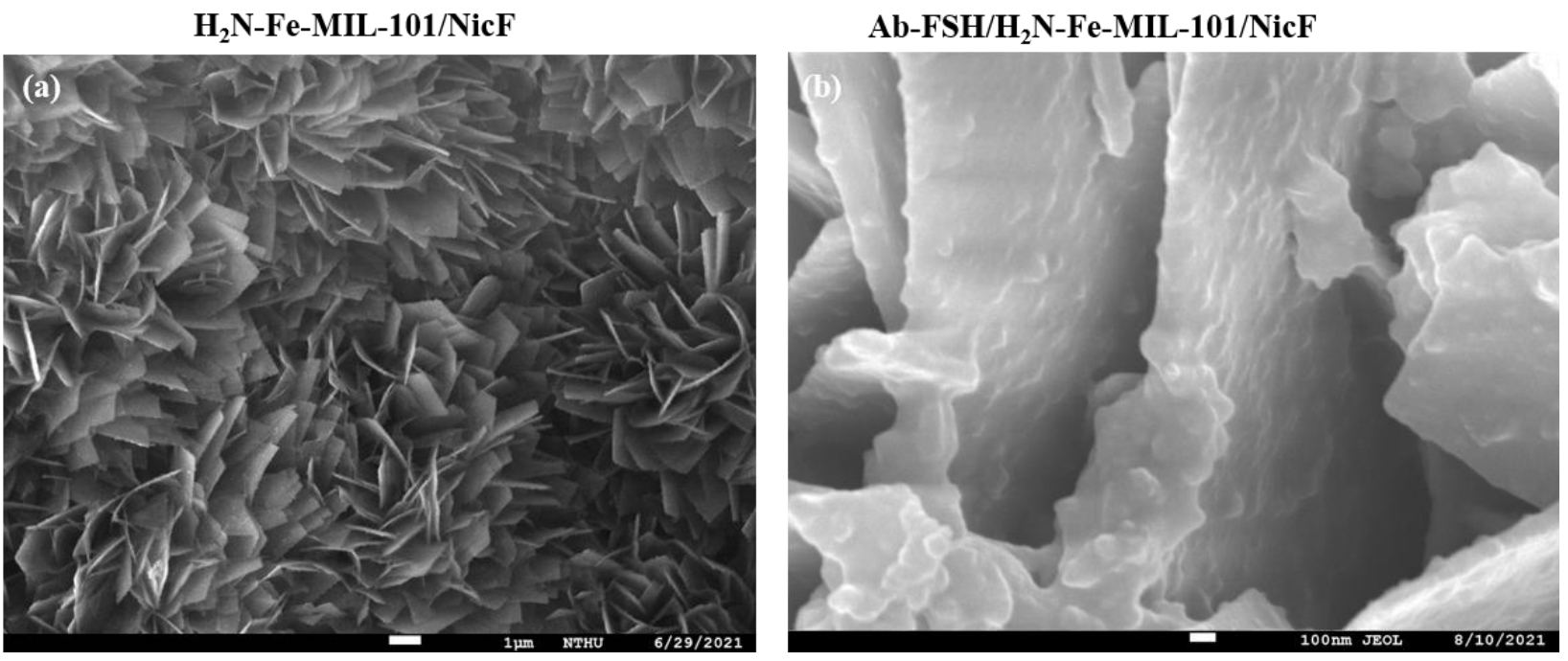
Figure S9. The mechanical stability of $\mathrm{H}_{2} \mathrm{~N}-\mathrm{Fe}-\mathrm{MIL}-101 / \mathrm{NicF}$ electrodes and $\mathrm{Ab}-\mathrm{FSH} / \mathrm{H}_{2} \mathrm{~N}-\mathrm{Fe}-$ MIL-101/NicF electrodes at pH 7.4.

\section{Quantification of Ab-FSH conjugated on $\mathrm{H}_{2} \mathrm{~N}$-Fe-MIL-101/NicF electrodes}

The number of Ab-FSH immobilized on $\mathrm{H}_{2} \mathrm{~N}-\mathrm{Fe}-\mathrm{MIL}-101 / \mathrm{NicF}$ electrodes was determined using ELISA. For this, a $100 \mu \mathrm{L}$ of FSH antigen $(1 \mu \mathrm{g} / \mathrm{mL})$ was coated in the ELISA plate overnight and then gently washed with $200 \mu \mathrm{L}$ of PBS once. It was then blocked with $100 \mu \mathrm{L}$ of $5 \%$ skim milk for 30 min and further washed with $200 \mu \mathrm{L}$ PBS thrice. A $100 \mu \mathrm{L}$ of different concentrations of standard Ab-FSH $(5,1,0.2,0.04,0.008,0.0016,0.00035 \mu \mathrm{g} / \mathrm{mL})$ was added and then incubated for $1 \mathrm{~h}$. After incubation, the plates were washed with $200 \mu \mathrm{L}$ of PBS three times. This is followed by the addition of $100 \mu \mathrm{L}$ of Anti-mouse Ig G (H+L) antibody conjugated HRP (10000 x diluted) and kept for $1 \mathrm{~h}$ incubation and washed again with $200 \mu \mathrm{L}$ of PBS three times. Finally, $100 \mu \mathrm{L}$ of TMB solution was added and kept for 5-10 min and the $1 \mathrm{~N} \mathrm{HCl}$ was added to stop the reaction and the microplate reader was used to collect the absorbance at $450 \mathrm{~nm}$.

The amount of Ab-FSH loaded on $\mathrm{H}_{2} \mathrm{~N}-\mathrm{Fe}-\mathrm{MIL}-101 / \mathrm{NicF}$ electrodes was calculated from the standard ELISA. For this, the calibration curve was generated from the standard solutions of AbFSH. The number of Ab-FSH bound on the electrodes were calculated from the supernatant collected after $2 \mathrm{~h}$ incubation of $\mathrm{H}_{2} \mathrm{~N}-\mathrm{Fe}-\mathrm{MIL}-101 / \mathrm{NicF}$ electrodes (Figure S10 and Table S2). Direct adsorption of Ab-FSH on $\mathrm{H}_{2} \mathrm{~N}-\mathrm{Fe}-\mathrm{MIL}-101 / \mathrm{NicF}$ electrodes resulted in a loading of $95 \%$ of Ab-FSH. 


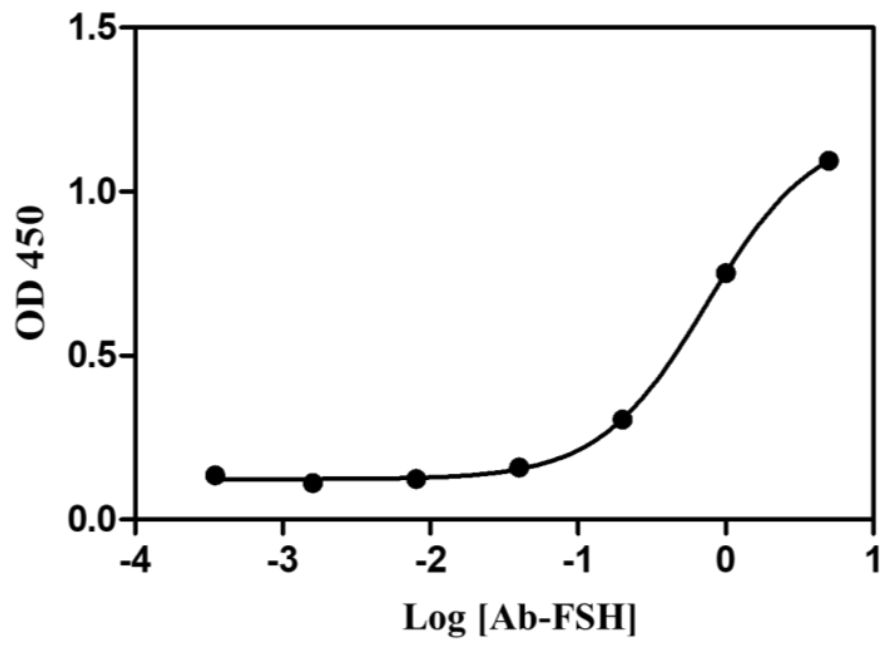

Figure S10. Calibration curve for the quantification of Ab-FSH obtained from ELISA.

Table S1. Comparison table for FSH detection methods and their sensitivities.

\begin{tabular}{lll}
\hline Method & Detection limit & References \\
\hline $\begin{array}{l}\text { Capillary electrophoresis with } \\
\text { chemiluminescence }\end{array}$ & $0.08 \mathrm{IU} / \mathrm{L}$ & 1 \\
Capillary immunosensor & $2.3 \mathrm{IU} / \mathrm{l}$ & 2 \\
Amperometric assay & $2.1 \mathrm{U} \mathrm{1^{-1 }} \mathrm{FSH}$ & 3 \\
SiNW-FET device & $0.72 \mathrm{fM}$ & 4 \\
MOF based immunosensor & $11.6 \mathrm{fg} / \mathrm{ml}$ & Present \\
& & work \\
\hline
\end{tabular}

Table S2. Concentration and absorbance details obtained from ELISA.

\begin{tabular}{cccc}
\hline $\begin{array}{c}\text { Added Antibody } \\
\begin{array}{c}\text { Concentration } \\
(\mu \mathrm{g} / \mathrm{mL})\end{array}\end{array}$ & $\begin{array}{c}\text { Corrected } \\
\text { Absorbance }\end{array}$ & $\begin{array}{c}\text { Supernatant } \\
\text { Concentration } \\
(\mu \mathrm{g} / \mathrm{mL})\end{array}$ & $\begin{array}{c}\text { Adsorbed } \\
\text { Antibody } \\
\text { Concentration } \\
(\mu \mathrm{g} / \mathrm{mL})\end{array}$ \\
\hline 5.0 & $1.093 \pm$ & $0.137 \pm$ & $4.863 \pm$ \\
& 0.030 & 0.021 & 0.021 \\
\hline
\end{tabular}




\section{References}

(1) Zhang, Y.; Zheng, H. Noncompetitive immunoassay for follicle-stimulating hormone in human serum using capillary electrophoresis with chemiluminescence detection. J Immunoassay Immunochem 2010, 31 (3), 193-204.

(2) Petrou, P. S.; Kakabakos, S. E.; Christofidis, I.; Argitis, P.; Misiakos, K. Multi-analyte capillary immunosensor for the determination of hormones in human serum samples. Biosens. Bioelectrons. 2002, 17 (4), 261-268.

(3) Pritchard, D. J.; Morgan, H.; Cooper, J. M. Simultaneous determination of follicle stimulating hormone and luteinising hormone using a multianalyte immunosensor. Anal. Chim. Acta 1995, 310 (2), 251-256.

(4) Lee, M.; Palanisamy, S.; Zhou, B. H.; Wang, L. Y.; Chen, C. Y.; Lee, C. Y.; Yuan, S. F.; Wang, Y. M. Ultrasensitive electrical detection of follicle-stimulating hormone using a functionalized silicon nanowire transistor chemosensor. ACS Appl. Mater. Interfaces 2018, 10 (42), 36120-36127. 